\title{
Synthesis of Cyclopentenediolates and Cyclopentane-1,2-diones by Carbonylation of Titanacyclobutane Complexes Prepared by Free Radical Alkylation
}

\author{
Charles A. G. Carter, ${ }^{1}$ Gary L. Casty, ${ }^{2}$ Jeffrey M. Stryker* \\ Department of Chemistry, University of Alberta, Edmonton, Alberta T6G 2G2 Canada \\ Fax +1 (780) 4928231; E-mail: jeff.stryker@ualberta.ca \\ Received 26 March 2001 \\ For the creativity, originality, and impact of his research, this manuscript is dedicated to Professor Ryoji Noyori, with deep admiration and \\ respect.
}

\begin{abstract}
The synthesis of titanium cyclopentenediolates by the double carbonylation of titanacyclobutane complexes is reported, a process known as the Bercaw carbonylation. The reaction is general for a range of titanacyclobutanes prepared by free radical alkylation of allyltitanium(III) precursors. Titanacyclobutane formation and carbonylation can be conducted in one pot without the isolation of sensitive intermediates. Subsequent conversion to lithium cyclopentenediolates and cyclopentane-1,2-diones provides access to a range of synthetically valuable organic products.
\end{abstract}

Key words: carbonylations, titanium, enediolates, metallacyclobutane complexes, cyclopentane-1,2-diones

Radical alkylation of permethyltitanocene $\eta^{3}$-allyl and related complexes provides substituted titanacyclobutane complexes by highly regioselective addition to the allyl central carbon. ${ }^{3}$ To realize the synthetic potential of this general process, the organic chemistry of the titanacyclobutane structural class must be further developed. One of the most interesting reactivity patterns already established for early transition metal dialkyl complexes is the transformation to metalloenediolates by reductive double carbonylation: the Bercaw reaction. ${ }^{4}$ This reaction has been previously used to convert titanium, zirconium, and hafnium metallacyclobutane complexes to the corresponding metalloenediolates or, after acid hydrolysis, to organic 2-hydroxycyclopentanones. ${ }^{5}$

Here we report that the Bercaw carbonylation reaction is general for a range of 3-substituted bis(pentamethylcyclopentadienyl)titanacyclobutane complexes, leading to the formation of the corresponding titanium cyclopentenediolate complexes cleanly and in high yield. The enediolates can be converted in high yield to lithium cyclopentenediolates by exchange with alkyllithium reagents or oxidized to cyclopentane-1,2-diones by an unexpected triphosgene-induced decomplexation, both unprecedented reaction processes with considerable synthetic potential.

With the exception of unsubstituted complex $\mathbf{1} \mathbf{f}^{6}$ the titanacyclobutane complexes $\mathbf{1}$ used in this investigation were prepared by the samarium(II)-mediated radical alkylation of bis(pentamethylcyclopentadienyl)titanium $\left(\eta^{3}-\right.$ allyl). ${ }^{3 \mathrm{a}, 7}$ More recently, we have reported that titanacyclobutane complexes $\mathbf{1}$ can be prepared more convenient- ly and in higher yields using a one-pot procedure starting directly with $\mathrm{Cp}_{2}{ }_{2} \mathrm{TiCl}^{8}$ (Equation). ${ }^{3 \mathrm{e}}$ This allylation/alkylation protocol avoids the isolation of allyltitanium(III) intermediates and minimizes manipulation of air- and water-sensitive materials.

The crude titanacyclobutane complexes 1 thus obtained can be carbonylated directly without further purification.

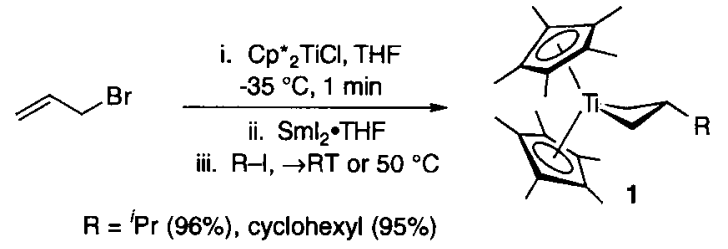

Equation

The carbonylation of titanacyclobutane complexes 1a-f proceeds in pentane at $-78^{\circ} \mathrm{C}$ under carbon monoxide (60 psig) to yield titanium cyclopentenediolate complexes 2a-f as the exclusive reaction products (Table). ${ }^{9}$ For optimal yields, the reaction mixture is maintained at low temperature for $0.5 \mathrm{~h}$ prior to warming to room temperature. ${ }^{11}$ The cyclopentenediolate complexes are isolated as noncrystalline powders after precipitation from the reaction mixture upon concentration and cooling to $-35^{\circ} \mathrm{C}$. Complexes 2a-f have been completely characterized and show characteristic infrared absorptions at $1430-1451 \mathrm{~cm}^{-1}$ $\left(v_{\mathrm{c}=\mathrm{c}}\right)$ and ${ }^{13} \mathrm{C}$ NMR resonances at $\delta 147-148\left(\mathrm{C}_{6} \mathrm{D}_{6}\right)$ for the olefinic carbons, fully consistent with previously reported examples of this structural class. ${ }^{4,12}$

Protolytic demetallation of bis(cyclopentadienyl)titanium cyclopentenediolate complexes has been previously reported $^{5 b, c, 12 a}$ For the permethyltitanocene template, protonolysis and aqueous acid hydrolysis both proved problematic. Under anhydrous conditions, the reaction of cyclopentenediolate 2a with gaseous $\mathrm{HCl}$ in pentane returns a very low yield of 2-hydroxy-4-isopropylcyclopentanone as a single (presumably trans) diastereomer. ${ }^{13} \mathrm{~A}$ moderate improvement in yield is obtained by using triflic acid: the reaction of enediolate complex $\mathbf{2 d}$ in ether at $0{ }^{\circ} \mathrm{C}$ returns 2-hydroxy-4-(1-phenylethyl)cyclopentanone 
Table Carbonylation of Titanacyclobutane Complexes to Give Titanium Cyclopentenediolates ${ }^{\mathrm{a}}$
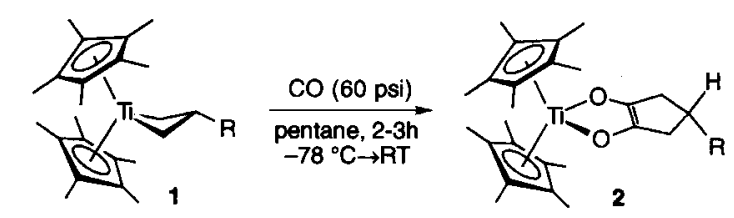

\begin{tabular}{cccc}
\hline Substrate (1) & Substituent (R) & Product (2) & Yield $^{\mathrm{b}}(\%)$ \\
\hline 1a & ${ }^{i} \mathrm{Pr}$ & 2a & 83 \\
1b & ${ }^{\mathrm{Bu}}$ & $\mathbf{2 b}$ & 75 \\
1c & $\mathrm{CH}_{2} \mathrm{Ph}$ & $\mathbf{2 c}$ & 88 \\
1d & $\mathrm{CH}(\mathrm{Me}) \mathrm{Ph}$ & $\mathbf{2 d}$ & 90 \\
1e & $\mathrm{CH}_{2} \mathrm{CH}=\mathrm{CH}_{2}$ & $\mathbf{2 e}$ & 70 \\
1f & $\mathbf{H}$ & 2f & 86 \\
\hline
\end{tabular}

${ }^{a}$ Reaction conditions: $60 \mathrm{psig} \mathrm{CO}$, pentane, $2 \mathrm{~h},-78^{\circ} \mathrm{C} \rightarrow \mathrm{RT}$; for a more detailed experimental procedure, see reference 9 .

${ }^{b}$ Isolated yields after purification.

3 in $43 \%$ yield; the metal is recovered in high yield as the dicationic bis(aquo)permethyltitanocene $4^{14}$ (Scheme 1). As anticipated, ketoalcohol $\mathbf{3}$ is formed as the expected mixture of two diastereomers after purification by preparative TLC. ${ }^{15}$

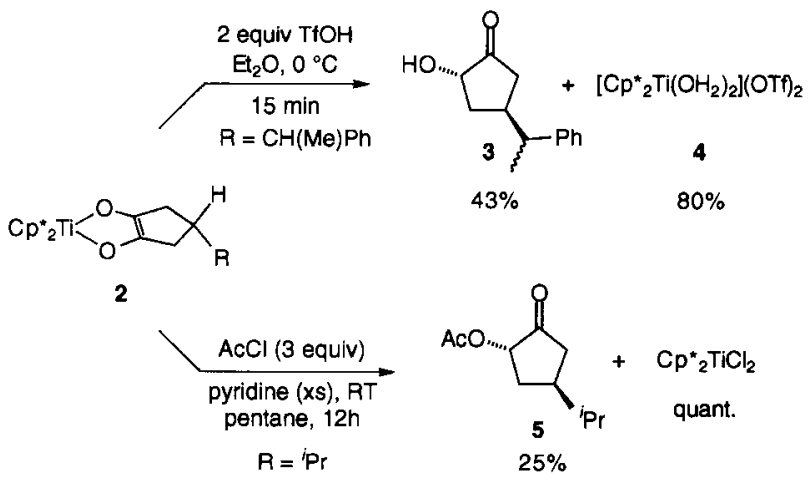

Scheme 1

Demetallation by acetylation is similarly inefficient, returning the $\alpha$-acetoxycyclopentanone $5^{16}$ in poor yield after treatment with acetyl chloride/pyridine (Scheme 1).

Two alternative demetallation pathways have been developed to address these deficiencies. Transmetallation to lithium is obtained upon treatment of cyclopentendiolate complexes 2 with two equivalents of methyl lithium at room temperature. As illustrated for complex $\mathbf{2 a}$, the reaction leads to the formation of $\mathrm{Cp}_{2}{ }_{2} \mathrm{TiMe}_{2}{ }^{17}$ and the corresponding lithium enediolate $\mathbf{6}$, both isolable in high yields (Scheme 2). ${ }^{18}$ The organic chemistry of lithium enediolates and related acyloin condensation intermediates has been extensively developed, connecting this titaniummediated manifold to a range of downstream transformations, including simple quenching to $\alpha$-ketols. ${ }^{19,20}$

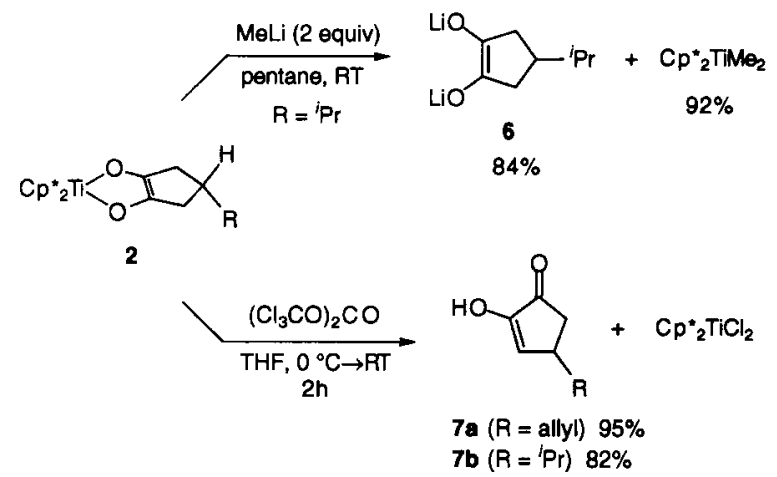

Scheme 2

The conversion of titanocene enediolate complexes to organic cyclic carbonates by treatment with phosgene has been reported, ${ }^{12 \mathrm{a}}$ a particularly unattractive option for further development. To circumvent the problem of phosgene toxicity, the use of the crystalline phosgene surrogate, bis(trichloromethyl)carbonate (triphosgene), ${ }^{21}$ was investigated for the demetallation of permethyltitanocene enediolate complexes. Triphosgene, however, unexpectedly mediates a novel oxidative cleavage reaction, converting the enediolates cleanly to 4-substituted cyclopentane-1,2-diones 7, which are isolated as the enol tautomers (Scheme 2). ${ }^{22}$ The organometallic fragment is returned largely as $\mathrm{Cp}^{*}{ }_{2} \mathrm{TiCl}_{2}$, although the mechanism of this transformation has yet to be investigated. Enolic cyclopentane-1,2-diones are well-precedented, ${ }^{23}$ both $7 \mathbf{a}$ and $\mathbf{7 b}$ exhibit spectroscopic properties fully consistent with the assigned structures. ${ }^{22}$

In combination with the alkylative titanacyclobutane formation, the double carbonylation of titanacyclobutane complexes thus provides a general method for the preparation of functionalized cyclopentane compounds at either the acyloin or $\alpha$-diketone oxidation state. Extension of this process to the synthesis of more highly substituted cyclopentenediolates requires further development of titanium templates that can accommodate the radical alkylation of substituted allyl ligands. ${ }^{3 c, d}$ Finally, we note that the development of additional pathways for converting substituted titanacyclobutane complexes to synthetically valuable organic products is also under investigation.

\section{Acknowledgement}

Financial Support from NSERC of Canada and the University of Alberta is gratefully acknowledged.

\section{References and Notes}

(1) Current address: NOVA Research and Technology Centre, NOVA Chemicals Corporation, $292816^{\text {th }}$ Street N.E., Calgary, Alberta T2E 7K7 Canada.

(2) Current address: Exxon Research and Engineering, 1545 Route 22 East, Annandale, New Jersey 08801, USA. 
(3) (a) Casty, G. L.; Stryker, J. M. J. Am. Chem. Soc. 1995, 117, 7814. (b) Ogoshi, S.; Stryker, J. M. J. Am. Chem. Soc. 1998, 120, 3514. (c) Carter, C. A. G.; McDonald, R.; Stryker, J. M. Organometallics 1999, 18, 820. (d) Greidanus, G.; McDonald, R.; Stryker, J. M., Organometallics, in press. (e) Carter, C. A. G.; Greidanus, G.; Chen, J.-X.; Stryker, J. M., submitted.

(4) (a) Manriquez, J. M; McAllister, D. R.; Sanner, R. D.; Bercaw, J. E. J. Am. Chem. Soc. 1978, 100, 2716. (b) Roddick, D. M.; Bercaw, J. E. Chem. Ber. 1989, 122, 1579.

(c) Theoretical mechanistic analysis: Hofmann, P.; Stauffert, P.; Frede, M.; Tatsumi, K. Chem. Ber. 1989, 122, 1559.

(5) (a) Brown-Wensley, K. A.; Buchwald, S. L.; Cannizzo, L.; Clawson, L.; Ho, S.; Meinhardt, D.; Stille, J. R.; Straus, D.; Grubbs, R. H. Pure Appl. Chem. 1983, 55, 1733. (b) Petersen, J. L.; Egan, J. W., Jr. Organometallics 1987, 6, 2007.

(c) Dennehy, R. D.; Whitby, R. J. J. Chem. Soc., Chem. Commun. 1990, 1060. (d) Beckhaus, R.; Wilbrandt, D.; Flatau, S.; Bohmer, W.-H. J. Organomet. Chem. 1992, 423, 211. (e) Tjaden, E.; Stryker, J. M. J. Am. Chem. Soc. 1993, $115,2083$.

(6) The unsubstituted titanacyclobutane complex $1 \mathbf{f}$ was prepared in $85 \%$ isolated yield by the addition of $\mathrm{LiEt}_{3} \mathrm{BH}$ (1 equiv) to the cationic $\mathrm{Ti}(\mathrm{IV})$ complex $\left[\mathrm{Cp}^{*}{ }_{2} \mathrm{Ti}\left(\eta^{3}\right.\right.$-allyl $\left.)\right] \mathrm{BPh}_{4}$ at $-78{ }^{\circ} \mathrm{C}$ under an atmosphere of ethylene to inhibit the decomposition of the titanacyclobutane under the reaction conditions (Carter, C. A. G., Ph.D. Dissertation, University of Alberta, 1998). Nucleophilic alkylation of $\left[\mathrm{Cp}{ }_{2} \mathrm{Ti}\left(\eta^{3}\right.\right.$-allyl $\left.)\right] \mathrm{BPh}_{4}$ has been previously reported: Tjaden, E. B.; Casty, G. L.; Stryker, J. M. J. Am. Chem. Soc. 1993, 115, 9814.

(7) $\mathrm{Cp}^{*}{ }_{2} \mathrm{Ti}\left(\eta^{3}\right.$-allyl): Luinstra, G. A.; ten Cate, L. C.; Heeres, H. J.; Pattiasina, J. W.; Meetsma, A.; Teuben, J. H. Organometallics 1991, 10, 3227.

(8) Fagan, P. J.; Manriquez, J. M.; Maata, E. A.; Seyam, A. M.; Marks, T. J. J. Am. Chem. Soc. 1981, 103, 6650. Liotta, F. J.; Duyne, G.; Carpenter, B. K. Organometallics 1987, 6, 1010.

(9) All products have been completely characterized (IR, ${ }^{1} \mathrm{H}$ and ${ }^{13} \mathrm{C}$ NMR, HRMS). Representative experimental procedure and characterization data for bis(pentamethylcyclopentadienyl)titanium(4-isopropylcyclopentene-1,2-diolate) 2a. In a drybox or otherwise under inert atmosphere, a Lab Crest aerosol pressure vessel (Andrews Glass Co.) fitted with Swagelok Quick connects, sampling port, and pressure gauge $^{10}$ was charged with 3-isopropyl titanacyclobutane 1a $(0.101 \mathrm{~g}, 0.251 \mathrm{mmol})$ and pentane $(10 \mathrm{~mL})$. The sealed vessel was cooled to $-78^{\circ} \mathrm{C}$ and pressurized with $\mathrm{CO}(60 \mathrm{psi}$ gauge pressure). After $0.5 \mathrm{~h}$ at low temperature, the cooling bath was removed and the reaction mixture stirred for an additional $2 \mathrm{~h}$. The pressure was released and the solution concentrated under reduced pressure. Cooling to $-35^{\circ} \mathrm{C}$ yielded complex $\mathbf{2 a}$ as a brown powder, pure by spectroscopic analysis $(0.095 \mathrm{~g}, 83 \%)$. Characterization data for 2a: IR (pentane cast, $\mathrm{cm}^{-1}$ ) 2960 , 2906, 2838, 1558, 1542, 1490, 1472, 1456, 1436, 1419, 1374, $1261,1089,1020,803,668 ;{ }^{1} \mathrm{H}$ NMR $\left(400 \mathrm{MHz}, \mathrm{C}_{6} \mathrm{D}_{6}\right) \delta 2.54$ (m, 4H, $\left.\mathrm{CH}_{2}{ }^{\prime} \mathrm{s}\right), 2.23(\mathrm{~m}, 1 \mathrm{H}, \mathrm{H} 4), 1.80\left(\mathrm{~s}, 15 \mathrm{H}, \mathrm{Cp}^{*}\right), 1.78(\mathrm{~s}$, $\left.15 \mathrm{H}, \mathrm{Cp}^{*}\right), 1.56\left(\mathrm{~m}, 1 \mathrm{H}, \mathrm{CH}\left(\mathrm{CH}_{3}\right)_{2}\right), 0.92(\mathrm{~d}, J=6.6 \mathrm{~Hz}, 6 \mathrm{H}$, $\left.\mathrm{CH}\left(\mathrm{CH}_{3}\right)_{2}\right) ;{ }^{13} \mathrm{C}$ NMR (100 MHz, $\mathrm{C}_{6} \mathrm{D}_{6}$, gated decoupling) $\delta$ $147.5(\mathrm{~s}, \mathrm{C}=\mathrm{C}), 121.9\left(\mathrm{~s}, C_{5} \mathrm{Me}_{5}\right), 121.0\left(\mathrm{~s}, C_{5} \mathrm{Me}_{5}\right), 42.7$ (d, $J=123 \mathrm{~Hz}, \mathrm{C} 4), 37.1\left(\mathrm{t}, J=128 \mathrm{~Hz}, C_{2}\right.$ 's), $34.3(\mathrm{~d}, J=128$ $\mathrm{Hz}, C \mathrm{HMe}_{2}$ ), 20.7 (q, $J=124 \mathrm{~Hz}, \mathrm{CHMe}$ ), 11.6 (q, $J=126$ $\left.\mathrm{Hz}, \mathrm{C}_{5} M e_{5}\right), 11.5$ (q, $\left.J=126 \mathrm{~Hz}, \mathrm{C}_{5} M e_{5}\right)$; HRMS (EI, $40 \mathrm{eV}$ ) calcd for $\mathrm{C}_{28} \mathrm{H}_{42} \mathrm{O}_{2} \mathrm{Ti}: 458.26643$, found 458.26642 .

(10) Detailed description of this pressure reactor: Messerle, L., in Experimental Organometallic Chemistry: A Practicum in Synthesis and Characterization; Wayda, A. L.; Darensbourg, M. Y., Eds.; American Chemical Society: Washington, D. C. (ACS Syposium Series 357), 1987; Chapter 7.4.
(11) Carbonylation reactions conducted at low pressure (10 psig) and high temperature $\left(45^{\circ} \mathrm{C}\right)$ proceed exclusively to give the organic cyclobutanone and $\mathrm{Cp} *{ }_{2} \mathrm{Ti}(\mathrm{CO})_{2}$. See reference $3 \mathrm{e}$.

(12) Titanocene and permethyltitanocene enediolates have also been prepared by oxidative ligand exchange using $\left(\mathrm{C}_{5} \mathrm{R}_{5}\right)_{2} \mathrm{Ti}(\mathrm{CO})_{2}(\mathrm{R}=\mathrm{H}, \mathrm{Me})$ and a 1,2-dione: (a) Dürr, $\mathrm{S}$.; Höhlein, U.; Schobert, R. J. Organomet. Chem. 1993, 458, 89. (b) For a titanium enediolate coordination complex prepared by a similar dione exchange, see Steinhuebel, D. P.; Lippard, S. J. J. Am. Chem. Soc. 1999, 121, 11762.

(13) Related 4-substituted-2-hydroxycyclopentanones have been reported: (a) Staudinger, H.; Ruzicka, L. Helv. Chim. Acta 1924, 7, 388. (b) Gurevich, A. I.; Kolosov, M. N.; Korobko, V. G. J. Org. Chem. USSR 1970, 6, 298. (c) Traverso, G. Gazz. Chim. Ital. 1971, 101, 225. (d) Eaton, P. E.; Sidhu, R. S.; Langford, G. E.; Cullison, D. A.; Pietruszewski, C. L. Tetrahedron 1981, 37, 4479. (e) Ogura, K.; Yamashita, M.; Suzuki, M. Tsuchihashi, G. Chem. Lett. 1982, 93.

(14) Thewalt, U.; Honild, B. J. Organomet. Chem. 1988, 348, 291.

(15) The diastereomeric $\alpha$-ketoalcohols $(\sim 1: 1)$ are very similar by ${ }^{1} \mathrm{H}$ and ${ }^{13} \mathrm{C}$ NMR spectroscopy, suggesting that the isomers are epimeric at the substituent methyl group.

(16) Related 4-substituted-2-acetoxycyclopentanones: Smith, A. B., III; Dunlap, N. K.; Sulikowski, G. A. Tetrahedron Lett. 1988, 29, 439 .

(17) Bercaw, J. E.; Brintzinger, H. H. J. Am. Chem. Soc. 1971, 93 , 2045. Bercaw, J. E.; Marvich, R. H.; Bell, L. G.; Brintzinger, H. H. J. Am. Chem. Soc. 1972, 94, 1219.

(18) Experimental procedure for lithium enediolate 6. In a Schlenck flask, bis(pentamethylcyclopentadienyl)titanium(4isopropylcyclopentene-1,2-diolate) $2 \mathbf{a}(0.054 \mathrm{~g}, 0.118 \mathrm{mmol})$ in pentane $(10 \mathrm{~mL})$ was treated with methyllithium $(0.170 \mathrm{~mL}$, $1.0 \mathrm{M}$ in ether) at room temperature. The reaction mixture was stirred for $4 \mathrm{~h}$, after which the solvents were removed in vacuo. The yellow residue was triturated with pentane under nitrogen and the resulting yellow solution filtered through a sintered-glass funnel. The solution was evaporated to dryness to afford $\mathrm{Cp}_{2}^{*} \mathrm{TiMe}_{2}(0.038 \mathrm{~g}, 92 \%)$ as a yellow powder. ${ }^{17} \mathrm{The}$ white pentane-insoluble residue, lithium cyclopentenediolate $6(0.015 \mathrm{~g}, 84 \%)$ was partially characterized by IR spectroscopy $\left(v_{\mathrm{C}}={ }_{\mathrm{C}}=1544 \mathrm{~cm}^{-1}\right)$ and by conversion to alkylation products by an established protocol. ${ }^{19}$

(19) Lithium enediolate alkylation: Wakamatsu, T.; Fukui, M.; Ban, Y. Synthesis 1976, 341. Wakamatsu, T.; Akasaka, K.; Ban, Y. Tetrahedron Lett. 1977, 2755. Wakamatsu, T.; Hashimoto, K.; Ogura, M.; Ban, Y. Synth. Commun. 1978, 8, 319.

(20) Acyloin condensation: Bloomfield, J. J.; Owsley, D. C.; Nelke, J. M. Org. React. 1976, 23, 259.

(21) Eckert, H.; Foster, B. Angew. Chem. Int. Ed. Engl. 1987, 26, 894.

(22) Experimental procedure and characterization data for 4-allyl2-hydroxy-2-cyclopentenone 7a. Bis(pentamethylcyclopentadienyl)titanium(4-allyl-cyclopentene-1,2-diolate) $2 \mathrm{e}(0.056 \mathrm{~g}$, $0.122 \mathrm{mmol}$ ) was dissolved in THF, cooled to $0{ }^{\circ} \mathrm{C}$, and added dropwise to a cold $\left(0^{\circ} \mathrm{C}\right)$ solution of triphosgene $(0.036 \mathrm{~g}$, $0.122 \mathrm{mmol}$ ) in THF. Stirring was continued for $1 \mathrm{~h}$, after which the solution was warmed to room temperature for an additional $1 \mathrm{~h}$. The volatiles were removed in vacuo and the oily red-brown residue triturated with hexane and filtered through celite to give a pale yellow-orange filtrate and a dark red residue of $\mathrm{Cp}^{*}{ }_{2} \mathrm{TiCl}_{2}(0.032 \mathrm{~g}, 67 \%)$. Evaporation of the hexane fraction gave crude product, which was purified by flash chromatography (4: 1 hexane/ether) to give 4-allyl-2hydroxy-2-cyclopentenone $7 \mathbf{a}$ as an off-white solid $(0.016 \mathrm{~g}$, 95\%). Characterization data for 7a: IR (cast, $\left.\mathrm{cm}^{-1}\right) 3350,3082$, 2913, 1703, 1648, 1634, 1395, 1198, 1099; ${ }^{1} \mathrm{H}$ NMR (360 
$\left.\mathrm{MHz}, \mathrm{CHCl}_{3}\right) \delta 6.51(\mathrm{~d}, J=2.9 \mathrm{~Hz}, 1 \mathrm{H}, \mathrm{H} 2), 5.78(\mathrm{~m}$ $1 \mathrm{H},=\mathrm{CH}$ allyl $), 5.45(\mathrm{~s}, 1 \mathrm{H}, \mathrm{OH}), 5.08\left(\mathrm{~m}, 2 \mathrm{H},=\mathrm{CH}_{2}\right.$ allyl $)$, 2.89 (m, 1H, H4), 2.60 (dd, $J=19.4,5.9 \mathrm{~Hz}, 1 \mathrm{H}, \mathrm{H} 5), 2.25$ (m, $2 \mathrm{H}, \mathrm{CH}_{2}$ allyl), 2.11 (dd, $\left.J=19.4,1.6 \mathrm{~Hz}, 1 \mathrm{H}, \mathrm{H} 5\right) ;{ }^{13} \mathrm{C} \mathrm{NMR}$ (100 MHz, $\mathrm{CHCl}_{3}$, gated decoupling) $\delta 203.1(\mathrm{~s}, \mathrm{C}=\mathrm{O}$ ), $152.5(\mathrm{~s},=C \mathrm{OH}), 135.1(\mathrm{~d}, J=154 \mathrm{~Hz},=\mathrm{CH}), 132.5(\mathrm{~d}$, $J=165 \mathrm{~Hz},=\mathrm{CH}), 117.5\left(\mathrm{t}, J=156 \mathrm{~Hz},=\mathrm{CH}_{2}\right), 39.6(\mathrm{t}$, $\left.J=121 \mathrm{~Hz}, \mathrm{CH}_{2}\right), 38.3\left(\mathrm{t}, J=132 \mathrm{~Hz}, \mathrm{CH}_{2}\right), 34.0(\mathrm{~d}, J=136$ $\mathrm{Hz}, \mathrm{C} 4$ ); HRMS (EI, $40 \mathrm{eV}$ ) calcd for $\mathrm{C}_{8} \mathrm{H}_{10} \mathrm{O}_{2}: 138.06808$, found 138.06771 .
(23) (a) Muxfeldt, H.; Wiegele, M.; Rheenen, V. V. J. Org. Chem. 1965, 30, 3573. (b) Dieckman, W. Chem. Ber. 1922, 55, 2470. (c) Staudinger, H,; Ruzicka, L. Helv. Chim. Acta 1924, 7, 442. (d) Hesse, G.; Bucking, E. Justus Liebigs Ann. Chem. 1949, 563, 31. (e) Schmidt, O. Th.; Eckert, R. Justus Liebigs Ann. Chem. 1958, 618, 71.

Article Identifier:

1437-2096,E;2001,0,SI,1046,1049,ftx,en;Y07901ST.pdf 